Primljeno: 21.02.2021.

Prihvaćeno: 01.03.2021.

Marija Tavčar ${ }^{1}$

Fakultet savremenih umetnosti u Beogradu Univerzitet Privredna akademija u Novom Sadu

\title{
PERFORMATIVNO TELO U VIRTUELNOM KOSTIMU
}

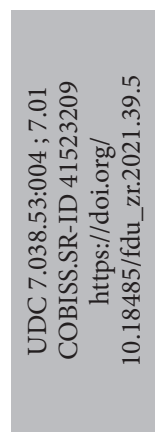

\begin{abstract}
Apstrakt
Predmet rada je da se uz pomoć koncepta „virtuelni kostim” analizira izvođačko telo odeveno u mocap sistem i otelovljeno u performativnom prostoru virtuelnog plesa. U simbiotskom odnosu sa tehnologijom, performativno telo se u tekstu definiše kao umnoženo, produženo i u konstantnom fluksu. Pretpostavka da se izvođač neprestano (re)konfiguriše i (re)definiše u interaktivnom prostoru performansa objašnjava se kroz teorijske koncepte: „otelovljenje kroz odevanje” Džoan Entvisl (Joanne Entwistle); kostima Sofije Pantovaki (Sofia Pantouvaki) i Ife Monks (Aoife Monks); performansa Suzan Kozel (Susan Kozel). Analizom (virtuelnog) kostima u performansu Vizualizacije kung-fu pokreta (Kung Fu Motion Visualization) Tobijasa Gremlera (Tobias Gremler) istražuje se kako tehnologija utiče na telesne reprezentacije u virtuelnim digitalnim performativnim formama.
\end{abstract}

\section{Ključne reči}

performans, virtuelni kostim, virtuelni ples, kostim, mocap

Umetničke prakse u sve većoj meri koriste savremene tehnološke sisteme pomoću kojih se prevazilaze tradicionalne granice forme i percepcije umetničkog dela. Sve više se eksperimentiše sa njenim kreativnim potencijalima u stvaranju novih oblika ekspresivnosti, estetskih doživljaja i interpretacija. Tehnologija smeštena u performativne umetnosti stvara i konceptualni prostor za istraživanje heterogenih odnosa između tela i tehnologije. Inkorporacijom tehnologije u kostim, materijalno i diskurzivno se proširuje polje delovanja performativnog tela, preispituju se njegove granice i struktura.

1 marija.tavcar@gmail.com 
Savremene tehnologije se sve brže razvijaju i prožimaju svaki deo ljudske realnosti. Informacije postaju glavni komoditet digitalnog doba, a brzina kojom se prenose predstavlja važan deo svakodnevnog života. Biti konstantno umrežen predstavlja imperativ savremenog društva. Ovo dovodi do razvoja uređaja koji omogućavaju lak pristup i razmenu informacija kao što su pametni telefoni (smartphones), pametni satovi (smartwatches), bežične slušalice, pametne naočare (smartglasses), uređaji za virtuelnu realnost (VR headset), fitnes narukvice, implanti itd.

Ekspanziju odeće i aksesoara koji inkorporiraju kompleksne tehnološke komponente prati stvaranje adekvatnih termina kao što su: nosiva ${ }^{2}$ tehnologija (wearable technology ili skraćeno wearables), nosivi kompjuteri (wearable computers), pametni tekstili (smart textiles), biotekstili (biotextiles) i još mnogi drugi.

Sabina Simor (Sabine Seymour) definiše nosivu tehnologiju kao tehnološke uređaje ili opremu koju korisnici mogu da oblače ili nose na svom telu, a u njih ubraja odevne predmete, implante i aksesoare (Seymour 2008: 14). U zavisnosti od potrebe korisnika, nosive tehnologije ispunjavaju različite funkcije: komunikaciju, aktivnost na društvenim mrežama, merenje otkucaja srca i pritiska, praćenje sna, proširenu realnost (augmented reality ili $A R)^{3}$, beskontaktno plaćanje itd. Tad Starner (Thad Starner) opisuje fenomen ovih „pametnih” odevnih predmeta i aksesoara kao „težnju za idealnim interfejsom - inteligentnim pomoćnikom koji je stalno prisutan i proširuje memoriju, intelekt, kreativnost, komunikacijske sposobnosti, čula i fizičke sposobnosti onoga ko ga nosi." (Starner 2002: 1).

Nosive tehnologije se sve više koriste i u umetničkim praksama kao što su interaktivna umetnost, virtuelna realnost, virtuelni i modni performans, a posebno u filmskoj i gejming industriji. One kao i video-igre „nisu samo izdvojen fenomen popularne kulture, već se prepliću sa drugim sferama umetnosti, kulture, medija, obrazovanja i života uopšte" (Mitrović 2020: 69).

2 Kao prevod reči wearable (eng.) u tekstu je izabran glagol nositi jer se odnosi na širi spektar odevnih predmeta i aksesoara nego glagoli kao što su oblačiti, obuvati itd. Glagol nositi ima opštiju upotrebu i odnosi se na sve predmete koji se nose na telu: odeću, obuću, torbe, različite ukrase, naočare, šešire itd.

3 AR tehnologija nam omogućava da kroz ekran (najčešće pametnog telefona) uz pomoć određene aplikacije vidimo elemente koji ne postoje u realnom svetu. Ovi elementi proširuju stvarnost koja nas okružuje samo ako je posmatramo kroz ekran. Aplikacija omogućava gledanje, ali ne i menjanje elemenata tj. interakcija sa njima nije moguća. Osim pametnih telefona, postoje i AR naočare, kroz koje pored realnosti oko sebe vidimo i dodatne elemente. 
Performativne forme predstavljaju idealan kontekst u kome se mogu izvoditi interakcije ljudskog tela i nosive tehnologije. Plesni studio, upućuje Suzan Kozel, predstavlja idealnu sredinu za fokusiranje na značaj i ulogu koju tehnologija ima u svakodnevnom životu (Kozel 2007:14). Konceptualne i eksperimentalne infrastrukture odnosa čoveka i tehnologije pojačane su u kontekstu izvođačkog dela.

\section{Kostimirana/performativna tela}

Pojam kostim unutar postojeće terminologije i u okviru savremenih teorija mode referira na različite tipove odeće koja ne pripada svakodnevnoj upotrebi već predstavlja deo scenske, festivalske, ceremonijalne prakse. Kostim, pored odeće uključuje i aksesoare, kao i kompleksnu oblast telesnih modifikacija. Savremeni teorijski diskursi vezani za oblast kostimografije proširuju definiciju scenskog kostima tvrdeći da određeni svakodnevni odevni predmeti postaju događaj/performans za sebe.

Iako je Elizabet Goep (Elizabeth Goepp) još 1928. godine u tekstu „Esej o filozofiji kostima” („An essay toward a philosophy of costume”) pokušala da skrene pažnju na filozofski značaj kostima u akademskim diskursima, ova oblast je i dalje relativno mlado polje istraživanja, posebno ako se uporedi sa teorijskim konceptualizacijama vezanim za scenografiju ili dramu. Smatra se da je i sam termin kostim nejasan zato što predstavlja opšti pojam koji se odnosi na čitav spektar fenomena. On je i odeća koja se nosi u specifičnom kontekstu performansa ili odeća koja se u prošlosti nosila van scene u svakodnevnom životu i odnosi se na istoriju mode i način odevanja kroz vreme. Termin kostim se dakle koristi da opiše fiksne načine oblačenja i ukrašavanja tela koji su se odnosili na određene performativne, istorijske, društvene i kulturne prakse odevanja.

U savremenim akademskim i umetničkim diskursima vezanim za prakse kostimografije, (scenski) kostim postaje i sredstvo (pre)ispitivanja položaja tela u umetnosti i performansu. Koncept kostima postaje metod kojim se telo kritički analizira.

Scenski kostim je usko povezan s reprezentacijama tela, a u isto vreme on je esencijalni deo performativnih umetnosti, pa kao takav i deo društvene i kulturne prakse. Dizajn kostima ima važnu ulogu u procesu razumevanja, interpretacije, definisanja i preispitivanja izvođačkog tela i njegovog karakte- 
ra u kontekstu performansa. Sam postupak stvaranja kostima u velikoj meri doprinosi procesu osmišljavanja performansa: formiranju likova, odnosa, značenja, prostora - zbog čega se dizajn kostima danas karakteriše kao izvođački čin/akcija u kome kostim postaje pripovedač i nosilac različitih interpretacija.

U simbiotskom odnosu sa izvođačem „kostim je perceptivno neodvojiv od glumčevog tela, a ipak [...] može se ukloniti. Kostim je telo koje se može skinuti" (Monks 2010: 42), tvrdi Ife Monks. Kostimirano telo postaje sredstvo kojim se izvođač konstituiše: otelovljuje unutar specifičnih društveno-kulturnih i individualnih interakcija. Ife Monks u knjizi Glumac u kostimu (The Actor In Costume) (2010) iznosi da zbog ,akumulativnog efekta performansa” čin posmatranja kostimiranog tela jeste čin formiranja tela glumca, „preoblikovanja njegovih kontura i rekonfiguracije njegovih značenja" (Monks 2010: 33). Akumulativan efekat performansa odnosi se na činjenicu da publika/učesnici dolaze iz različitih društvenih i kulturnih konteksta, s različitim predznanjima koja se prožimaju u trenutku izvođenja. Telo glumca nije jedinstveno, niti stabilno, ono se umnožava, vizuelno i značenjski menja u interakciji s recipijentima performansa. Scenski kostim je materijalno fiksan. Međutim u kontekstu izvođačkih umetnosti, njegova značenja postaju fluidna, pregovarana i izvođena u interakciji između svih učesnika performansa.

Pantovaki povlači paralelu između pojma „otelovljena interakcija” (embodied interaction) (Dourish 2015: 6) Pola Doriša i kostima. Ona interpretira Dorišov termin kao vezu akcije i značenja kroz telesno iskustvo. Koncept otelovljene interakcije je preuzet iz diskursa IKT (informacione i komunikacione tehnologije, na engleskom information and communications technology ili technologies) i društvenih teorija: dakle kao produkt prožimanja disciplina informatike i računarstva $s$ jedne i društvenih nauka s druge strane. Doriš objašnjava pojam otelovljenja kao osobinu da se neko/nešto manifestuje u svetu. Ta manifestacija podrazumeva prelazak iz sveta ideja u oblast svakodnevnog iskustva i ne predstavlja samo jednostavnu fizičku manifestaciju već i druge aspekte svakodnevnog života. Kao primer Doriš daje razgovor koji se ne manifestuje samo fizički (zvučnim talasima koji putuju kroz vazduh), već i kroz kontekst u kome se realizuje i kroz učešće isto tako otelovljenih ljudi, odnosa, akcija i razumevanja. Otelovljenje ili manifestacija tako označava ne fizičku realnost već status učešća: participaciju. Interakcija se dešava u svetu (fizičkom i društvenom), koji formira njenu suštinu i značenje. Ona se ne manifestuje jednostavnim fizičkim kontaktom već podrazumeva okolnosti i niz određenih situacija koji joj daju značenje i vrednost. 
Dakle kroz praksu kostimiranja koja se manifestuje u određenom prostoru i vremenu, a uslovljena je društveno-kulturnim i individualnim kontekstima, stvara se performativno telo kao produkt konstantne interakcije između svih učesnika izvođačkog dela. Kostim kroz telesno iskustvo aktivira neprestanu komunikaciju u vidu iščitavanja i interpretiranja njegovih vizuelnih tekstova. Performativno telo se otelovljava kroz interakciju sa svim učesnicima i elementima izvođačkog dela.

Slično Dorišovom konceptu, Džoan Entvistl (Joanne Entwistle) razvija interpretaciju komunikacije kroz akciju otelovljenja, koju naziva „odevanje kao otelovljenje" (Entwistle 2000b: 324). Svoju premisu koncipira koristeći se istorijskim i društvenim kontekstom unutar sociološke teorije mode. U eseju „Moda i neukusno telo: odevanje kao praksa otelovljenja” („Fashion and the Fleshy Body: Dress as Embodied Practice") Entvislova opisuje ljudska tela kao „odevena tela”, što je prvobitno teorijski koncept Brajana Tarnera (Bryan Turner). Preciznije Tarner na početku knjige Telo i društvo (The Body and Society, 1985) tvrdi da „postoji očigledna i upadljiva činjenica o ljudskom biću, da ono ima telo i da ono jeste telo" (Turner 1985: 10), i dalje kroz svoju analizu želi da izrazi ideju da su ljudska tela zapravo uvek odevena tela. Odevanje je bazični fenomen društvenog života i na osnovu antropoloških istraživanja odnosi se na sve nama danas poznate kulture. U svim oblicima društava, ljudi su na neki način odevali/ukrašavali telo: odećom, ukrasima, kozmetikom, tetoviranjem, oslikavanjem, skarifikacijom itd. Način odevanja pretvara fizičko telo u društveno-kulturno telo: čini ga prepoznatljivim i daje mu slojeve značenja u određenom kontekstu. Odevanje, smatra Entvislova, „ne služi samo da bi zaštitilo našu smernost i ne odražava samo prirodno telo ili, u tom slučaju, dati identitet; ono ulepšava telo [...] dodajući čitav spektar značenja telu" (Entwistle 2000b: 324).

Koncept otelovljenja predstavlja „živo, iskustveno telo koje je artikulisano kroz praksu odevanja” (Entwistle 2000a: 4). Definisano na ovaj način „otelovljenje kroz odevanje" (isto.) smešta se u centar analize teorijskog diskursa mode. Entvislova predstavlja telo kao „produkt dijalektike između prirode i kulture" (isto.), navodeći da se moda otelovljuje u svakodnevnom životu i da komunicira (pre)noseći mnogobrojna značenja. Prema tome, pojam otelovljenja predstavlja „učešće i označavanje kroz telesno iskustvo" (Pantouvaki 2014: 186), a interakcija je definisana kao akcija komuniciranja kroz odeveno telo. 
Iskustvo kostimiranog izvođača uspostavlja „okruženje lika, neodvojivo od lika” (Entwistle 2000a: 187) kao „aktivni i perceptivni medij lika” (isto.) posmatranog od strane publike kroz kontekste njenih internih iskustava. Kostimirano telo se ponaša na specifičan način u određenom vremenu, prostoru i kontekstu, i na taj način uslovljava kako su likovi reprezentovani i kako stupaju u interakciju u specifičnom performativnom kontekstu. Monksova približnije objašnjava ovaj teorijski pristup ističući višeslojnost komunikacije između izvođača i kostima, kostimiranog tela i publike unutar izvođačkog dela i njegove percepcije (Monks 2010: 40). Stoga se kostim u kontekstu performansa može opažati ne samo kao društveno-kulturni produkt ili vizuelno-materijalna stvar već i kao živa, iskustvena pojava koja komunicira sa recipijentima kroz vreme i prostor.

„Kostim se odnosi na telesne prakse i značenja, a artikulisan je kroz semiotičke kodove i pojmovne asocijacije" tvrdi Pantovaki (Pantouvaki 2014: 186). Telesne akcije i njihove reprezentacije kroz kostim stvaraju interakcije pomoću kojih se doživljava, iščitava i opaža kostimirano telo. Izvođač se otelovljuje kroz telesnu praksu kostimiranja, u određenom prostoru, kroz neprestanu interakciju svih učesnika performansa. Kostim je, dakle, esencijalni deo performansa jer ne samo da se zahvaljujući njemu otelovljuje izvođač, već i nastaju značenja, ostvaruje se komunikacija, što utiče na stvaranje i uslojavanje tekstova u samom izvođačkom delu.

\section{Otelovljenje izvođača u virtuelnom performativnom prostoru pomoću mocap/ performance capture tehnologije}

Motion capture, motion tracking ili mocap su termini koji označavaju proces snimanja pokreta i, zatim, prenošenja tih pokreta na digitalni model. Primenjuje se u vojnoj i medicinskoj industriji, u sportu, industriji zabave itd. Dakle mocap predstavlja proces digitalnog snimanja pokreta koje se transponuje u model smešten u projektovanom ili ekranskom 3D prostoru. Budući da poseduje ovakve tehnološke kapacitete, mocap premešten u polje performativnih umetnosti ima ekspresivni potencijal da kreira inovativne estetske forme $\mathrm{u}$ interaktivnim umetničkim sistemima, kao i nove reprezentacije izvođačkog tela.

Pored motion capturie sistema, u filmskoj i gejming industriji kao i u mnogim drugim kreativnim delatnostima koristi se i performance capture, koji omogućava da se na digitalni lik preslika pun opseg glumačkih sposobnosti 
od pokreta tela do ekspresije lica. Korišćenje performance capture sistema je postalo važan deo stvaranja likova u video-igrama, animacijama i na filmu, pa se otvaraju čitave škole koje se isključivo bave obučavanjem izvođača za ovaj tip glume i plesa.

Motion capture nije nov fenomen i u prošlosti se koristio da okvirno snimi pokretanje tela. Danas su ovi sistemi toliko osetljivi i efikasni u snimanju glumačkog izvođenja da mogu da „uhvate” i najsuptilnije detalje u gestikulaciji lica ili ruku. U kombinaciji sa real-time tehnologijom koja omogućava ovim sistemima da u realnom vremenu projektuju glumački performans na digitalni model, stvara se prostor za nova (scenska) izvođenja i interaktivna iskustva.

Nekolicina savremenih umetnika koristi mocap sisteme i stvara na granici tradicionalnih performativnih formi i savremene (nosive) tehnologije izvodeći digitalne/virtuelne plesove. Mocap u ovom kontekstu predstavlja tehnologiju pomoću koje se izvođač otelovljuje u virtuelnom prostoru, a njegov kostim/telo se duplicira. U realnom prostoru on izvodi performans u odeći sa sistemom za motion capture, a u virtuelnom se manifestuje u virtuelnom kostimu. Pored toga što predstavlja materijalnu reprezentaciju izvođača, pojam virtuelni kostim postaje koncept preko koga se (pre)ispituje performativno telo i (re)definiše uloga koju tehnologija ima u savremenim umetničkim praksama.

Suzan Kozel u knjizi Closer približava performans, digitalne tehnologije i filozofski fenomenološki pravac kako bi razotkrila i istražila karakteristike veza koje se stvaraju u odnosima čovek-kompjuter, čovek-kompjuter-čovek, i dokazala kako nove tehnologije postaju „ekstenzije načina na koji mislimo, na koji se krećemo i dodirujemo" (Kozel 2007: xiv). Performans, tvrdi Kozelova, iziskuje da izvođač refleksivno pristupi izvođenju i donese „odluku da vidi/ oseti/čuje sebe dok izvodi performans, i odluku da vidi/oseti/čuje druge kako izvode dok ih ona posmatra" (isto.). Dinamika reverzibilnosti u performansu ogleda se u svesti o stalnom stanju prihvatanja uticaja iz spoljašnje sredine, $i$ aktivnom odnosu između onoga unutar i izvan tela.

Performans nije jednosmerno izlaganje tela u spoljašnjost već i svesna transformacija akcije/reakcije u odnosu na kontekst: svest o okolini, prilagođavanje i odgovor $\mathrm{u}$ toku interakcije. Telo se zbog interkorporealnosti (intercorporeality) i svojih različitih manifestacija tokom performansa menja, restrukturira. Koncept interkorporealnost $\mathrm{u}$ isto vreme odnosi se na društveni 
karakter tela i telesni karakter društvenih odnosa zato što ističe ulogu društvenih interakcija u konstruisanju i ponašanju tela. „Iskustvo telesne manifestacije nikada nije lično, već je uvek posredovano stalnim interakcijama $s$ drugim ljudskim i neljudskim telima." (Weiss 1999: 5). Tako se tokom performansa stvaraju uzročno-posledični odnosi reagovanja, preispitivanja, (pre) oblikovanja između učesnika.

Slično Kozelovoj, Juhan Kim (Joohan Kim) tvrdi da digitalne sredine ostvaruju nove mogućnosti za interkorporealne prakse, što fenomen interkorporealnosti čini važnim za razumevanje "procesa kroz koje se telo proizvodi” (Hansen 2006: 79) u digitalnim sredinama. Tehnologiju ne treba posmatrati kao instrument ili alat. Ona u kontekstu performansa postaje filter, propustljiva membrana. Tehnologija u sprezi s kostimom stvara novi prostor za istraživanje performativnog tela. Ostvaruje se potencijal za nova otelovljenja, a samim tim se (re)definišu i (re)konceptualizuju granice tela i tehnologije, percepcije, interakcije sa prostorom, vremenom i drugim telima.

Performativno telo odeveno u performance capture postaje „prag između dva sveta” (Palumbo 2000: 38): virtuelnog i realnog. Njegove percepcije se umnožavaju. Ono oscilira između različitih prostornih konteksta, u isto vreme je prisutno i odsutno, telesno i bestelesno, organsko i tehnološko itd. Izvođač se više ne formuliše integralnom, ograničenom telesnom manifestacijom, on je otvoren sistem, mreža ili sklop digitalnog i telesnog.

Performance capture materijalizuje telo podložno mutaciji i manipulaciji. Ono je artikulisano negde između tela, kostima, prostora i tehnologije. Tehnološka komponenta kostima u ovaj sistem unosi nove čulnosti i percepcije kroz proces otelovljenja. Izvođačka tela su u povratnoj sprezi s tehnologijom i nemoguće je razlikovati organsko od tehnološkog jer funkcionišu kao jedinstven sistem. Dženifer Parker-Starbak (Jennifer Parker-Starbuck) definiše koncept cyborg performance kao izvođačku praksu na granici različitih koncepcija tela i tehnologije - tehnologija i izvođači na sceni predstavljaju jedinstvo u stvaranju i razumevanju performativnog dela (Parker-Starbuck 2011: 168).

Materijalizovan u procesu stalnog (re)konstruisanja kroz permanentnu interakciju između tela, tehnologije, učesnika i prostora performansa, izvođač postaje fluidan i fluktuirajući. Performativno telo u nosivoj tehnologiji nije stabilno u svojoj celovitosti, ono je skup zamenjivih delova/sistema koji se (re)konstruišu i transformišu u interakciji sa prostorima unutar/izvan nje- 
ga. Kostim nije samo ekstenzija ili dodatak, on je homogeni deo promenjive strukture izvođača u procesu neprestane artikulacije.

Virtuelni kostim materijalno i konceptualno omogućava da se kroz formu (interaktivnog) digitalnog performansa preispitaju telesne granice izvođača i odnosi koji se ostvaruju kroz umrežavanja sa tehnologijom. Smeštanjem mocap-a ili performance capture sistema u polje performansa kreira se nov ekspresivni prostor za (pre)ispitivanje uticaja tehnologije na umetnost, društveno-kulturne i individualne percepcije/reprezentacije (performativnog) tela i različite umetničke/konceptualne forme. Mocap kao kostim pozicionira izvođača u hibridni prostor novomedijske umetnosti, pri čemu se njegovo performativno telo i subjekat proširuju stvarajući nova otelovljenja kroz praksu odevanja nosive tehnologije.

\section{Virtuelni kostim/ples}

U kinetičkom video-zapisu pod naslovom Vizualizacija kung-fu pokreta, ${ }^{4}$ koji je stvoren za izložbu posvećenu kung-fu borilačkoj veštini u Muzeju kulturnog nasleđa u Hongkongu, umetnik Tobijas Gremler, inspirisan dinamikom pokreta i filozofijom ove borilačke veštine, koristi mocap tehnološki sistem kako bi stvorio svojevrsan virtuelni balet. U stvaranju ovog interaktivnog dela umetnik je koristio pokrete kung-fu majstora bak mei stila (Bak Mei Style) Li Šek Lina (Lee Shek Lin) i majstora lung jing stila (Lung Ying Style) Vong Jiu Kaua (Wong Yiu Kau), kako bi mapirao njihove pokrete i animirao ih u realnom vremenu pomoću mocap tehnologije.

Vizualizacija kung-fu pokreta sastoji se od četiri glavne varijacije sa podvarijantama: Varijacija 1: Tkanina istkana vremenom (Variation 1: Fabric weaved by time), Varijacija 2: Brzina se transformiše u materiju (Variation 2: Velocity transforms into matter), Varijacija 3: Širenje u prazninu (Variation 3: Expanding into emptiness), Varijacija 3.1: Širenje u prazninu (Variation 3.1: Expanding into emptiness), Varijacija 4: Rekonstrukcija oblika pokretom (Variation 4: Reconstructing shapes from motion), Varijacija 4.1: Rekonstrukcija oblika pokretom (Variation 4.1: Reconstructing shapes from motion), Varijacija 4.2: Rekonstrukcija oblika pokretom (Variation 4.2: Reconstructing shapes from motion), Varijacija 4.2: Forma prati vreme (Variation 4.2: Form folows time). Svaka varijacija ima određenu manifestaciju performativnog tela u virtuel-

4 Video na sajtu: Gremmler, Tobias, Kung Fu Motion Visualization, https://vimeo.com/163153865, [Pristupljeno: 18. 02. 2021, 21.30]. 
nom prostoru: u prvoj je to tkanina, zatim u drugoj prašina, u trećoj iglice i na kraju u četvrtoj DNK lanac. Podvarijante su različite kinetičke i vizuelne ekspresije ovih manifestacija.

Tobijas Gremler koristi mocap nosivu tehnologiju kako bi prikazao ono što on naziva „nevidljivo”. Pokreti borilačkih veština ovih majstora mapiraju se i primenjuju na 3D virtuelne modele, koji reprezentuju apstraktne forme kao što su oblak digitalne prašine, tekstura tkanine i virtuelni model DNK lanca. Rezultat je animacija koja transformiše precizne pokrete borilačke discipline kung-fua u geometrijske i apstraktne forme. Ljudska figura je fragmentirana, jedva se naslućuje tek kroz sekvence linija, tačaka i poteza koji podsećaju na položaje tela. Smenjivanjem minimalističkih i slojevitih formi, stalnim transformacijama silueta u konture, umetnik pokušava da predstavi kompleksne i virtuozne kung-fu metode, istovremeno (pre)ispitujući granice izvođačkog tela.

Izvođači se simultano otelovljuju u virtuelnom i realnom prostoru kroz praksu odevanja mocap sistema. Performativna tela kung-fu majstora izvode zahtevne pokrete u realnosti, čime aktiviraju tehnologiju koja transponuje izvođače $u$ virtuelni prostor, gde se njihova tela transformišu u fluidne forme virtuelnog kostima. Aktivirani pokretom, tehnološki kostimi umnožavaju izvođačka tela i deluju u dve različite sredine. Otelovljeni/udvostručeni između digitalnog i organskog, virtuelnog i realnog prostora, izvođači ovog kinetičkog animiranog dela predstavljaju hibridne entitete koji se aktiviraju u interakciji tehnologije i pokreta tela.

Virtuelni kostim transformiše izvođače kroz različite telesne reprezentacije. Ovako (virtuelno) kostimirana tela postaju dobar diskurzivni prostor (pre) ispitivanja granica i analize odnosa tehnologije i izvođača. Mocap kao kostim predstavlja prostor u kome se ostvaruje interakcija fizičkog tela i njegove virtuelne reprezentacije, tačka u kojoj se ova dva stapaju čineći jedan heterogeni entitet. Dakle granice organskog performativnog tela se pomeraju i proširuju u simbiozi sa tehnologijom. Ljudsko biće postaje uređaj „uz pomoć koga će svest prelaziti iz jednog sveta u drugi, gde i kada to poželi." (Stojković 2012: 130).

U Vizualizaciji kung fu-pokreta virtuelni kostimi stalno (re)konstituišu izvođačko telo u procesu fluktuiranja iz forme u formu, obrisa u obris referišući na savremeni ljudski heterogeni subjekat, koji kao diskurzivna tvorevina nastaje u konstantnom pokretu između različitih društveno-kulturnih i in- 
dividualnih konstrukata. Manifestacija izvođača u virtuelnom prostoru kao „objekat koji izvodi na sceni - sa i bez prisustva ljudskog bića/biološkog elementa provocira ne samo status tela u performansu (umetnika, publike i izvođačkog tela), već i status njihovog subjektiviteta." (Stojanović 2016: 171). Performativno telo izmiče homogenoj, ograničenoj strukturi kroz metamorfozu organskog u virtuelno i obrnuto.

Izvođač je entitet u neprestanom procesu nastajanja unutar interaktivnog performativnog prostora. Njegovo telo je nestabilna struktura koja se (re) definiše kroz različite interpretacije. Kostim više nego „što uokviruje i strukturira” izvođača, „preplavljuje njegove granice” (Hannah 2014: 20) i „nadvladava njegove okvire" (isto.). Tako je granica performativnog tela nestabilna, umnožena, vizuelno i značenjski u stalnom pregovaranju i (re)konfiguraciji. Izvođač je „mešavina, kolekcija raznovrsnih komponenti, materijalno-informacioni entitet čije su granice u stalnoj konstrukciji i rekonstrukciji." (Hayles 1999: 3).

Koncept virtuelnog kostima konstituiše performativno telo kao heterogeni entitet kroz čije transformacije se pregovaraju i erodiraju njegove granice. $U$ tom smislu tehnologija produžava ljudsko telo i obogaćuje njegovo iskustvo, percepciju i značenja. Performativno telo je „unapređeno” u simbiozi sa tehnološkim sistemom, a polje njegovog delovanja se širi unutar odnosa prirodnog, društvenog i tehnološkog.

\section{Zaključak}

Savremene tehnologije prodiru u teorijske i praktične prakse umetnosti. One ne samo da utiču na stvaranje novih umetničkih formi već su „ulaskom u sajberprostor, odnos umetnika prema institucijama umetnosti, kao i tradicionalni modeli prikazivanja dovedeni u pitanje." (Mevorah 2016: 225). Između ostalog, tehnologija zauzima važno mesto u oblasti savremenih performativnih praksi virtuelne realnosti, animacije, gejminga, filmske industrije, virtuelnog performansa, interaktivnih, novomedijskih umetnosti itd. Samim tim treba (re)definisati u kojoj meri ona utiče na stvaranje novih (umetničkih) formi, reprezentacija, interpretacija itd.

Performans je idealno mesto za preispitivanje fluidne razmene akcije/reakcije tela i tehnologije, i načina na koji se čovek transformiše i komunicira unutar ovih veza. Dorita Hana (Dorita Hannah) zato predstavlja teatar kao prostor 
i događaj u kome se i tokom kojeg se razumevaju, razmatraju i međusobno prožimaju kulturna, mitska i politička pitanja današnjice. Ovde pomenuti koncepti prostora i događaja (teatar) prevazilaze svoja osnovna značenja i odnose se na prepoznavanje i kritiku različitih izvođačkih dimenzija u svakodnevnom životu. Tako je svakodnevni život protkan pozorištem i „kreće se između stvarnog sveta i njegove umetničke (re)prezentacije" (Hannah 2014: 17). S obzirom na to da je tehnologija postala neizbežan deo kulturne i socijalne realnosti, njenom uticaju na društvo, čoveka, telo, prostor, umetnost itd. kritički se može pristupiti i kroz medij izvođačkih umetnosti. Scena tako postaje prostor eksperimentisanja i preispitivanja uloge tehnologije u životu savremenog ljudskog bića.

Kostim je relativno mlado akademsko polje istraživanja. Definiše se kao konstitutivni deo izvođača, usko povezan sa kulturnim, društvenim i individualnim reprezentacijama i interpretacijama performativnog tela. Konceptualizacijom kostima se analiziraju različita otelovljenja izvođača i interakcije koje se ostvaruju u kontekstu performansa između svih njegovih učesnika i prostora. Kostim postaje sredstvo (pre)ispitivanja i (re)definisanja položaja tela u performativnim umetnostima.

Hibridni spoj kostima i tehnologije manifestuje se u fenomenu virtuelnog kostima i predstavlja idealan konceptualni prostor za analizu i eksperimentisanje sa novim interakcijama, otelovljenjima, estetikama, interpretacijama itd. Virtuelni kostim pomera granice klasičnog pristupa kostimografiji i performansu, što nalaže da se istraže uticaji novih tehnologija na kostimografiju i izvođačko telo.

Kostimi koji integrišu tehnologiju nude perspektivnu osnovu za (pre)ispitivanje različitih društvenih, kulturnih i individualnih tekstualnosti; stvaranje novih narativa, estetskih $i$ čulnih iskustava, ekspresivnosti i interpretacija ljudskog tela otelovljenog kroz odevanje i kostim; istraživanje novih performativnosti i estetika u izvođačkim umetnostima; eksperimentisanje sa estetskim, konceptualnim i perceptivnim iskustvima u hibridnoj sferi interaktivnih i novomedijskih umetnosti kao i za još mnoga druga istraživanja. 


\section{Literatura}

- Entwistle, Joanne (2000a) The Fashioned Body-Fashion, Dress and Modern Social Theory. Cambridge: Polity Press.

- Entwistle, Joanne (2000b) "Fashion and the Fleshy Body: Dress as Embodied Practice", Fashion Theory: The Journal of Dress, Body \& Culture, Vol. 4, No. 3, pp. 323-347.

- Entwistle, Joanne, Wilson, Elisabeth (eds.) (2001) Body Dressing: Dress, Body, Culture. Oxford: Berg.

- Goepp, Elizabeth (1928) "An essay toward a philosophy of costume", The Quarterly Journal of Speech, 14: 3, str. 396-411.

- Hannah, Dorita (2014) "Alarming the heart: Costume as performative body-object-event", Scene, Vol. 2, No. 1-2.

- Hansen, Mark (2006) Bodies in Code: Interfaces with Digital Media. New York, Routledge: Taylor \& Francis Group.

- Kozel, Susan (2007) Closer: performance, technologies, phenomenology. Cambridge and London, MIT Press.

- Mevorah, Vera (2016) „Internet umetnost u institucionalnom kontekstu: budućnost i izazovi digitalne umetnosti u Srbiji”, Zbornik radova Fakulteta dramskih umetnosti, br. 29, Beograd, str. 217-233.

- Mitrović, Biljana (2020) „Studije video-igara: Janus teorije i prakse“, Zbornik radova Fakulteta dramskih umetnosti, br. 37, Beograd, str. 59-71.

- Monks, Aoife (2010) The Actor in Costume. London: Palgrave Macmillan.

- Palumbo, Maria (2000) New Wombs: Electronic Bodies and Architectual Disorders. Basel: Birkhauser.

- Pantouvaki, Sofia (2014) "Embodied interactions: Towards an exploration of the expressive and narrative potential of performance costume through wearable technologies", Scene, Vol. 2, No. 1-2.

- Seymour, Sabine (2008) Fashionable Technology: The Intrasection of Designe, Fashion, Science and Technology. Wien: Springer.

- Stojanović, Dragana (2015) "Seeing (my) body looking back at me, once again and multiplied: the digital alibis of the subject", Going Digital: Innovations in the contemporary life, book of abstracts, STRAND - Sustainable Urban Society Association Belgrade, Belgrade, pp. 15.

- Stojanović, Dragana (2016) “The Playful Face of the Performing Object: The Perplexed Relations of the Artist and the Audience in the Presence of an Artificial Body" in Cvejić, Žarko, Filopović, Andrija, Petrov, Ana, The Crisis in the Humanities: Transdisciplinary Solutions, Cambridge: Cambridge Scholar Publishing, pp. 169-173. 
- Stojković, Mirko (2012) „Video igre na prenosivim uređajima”, Zbornik radova Fakulteta dramskih umetnosti, br. 22, Beograd, str. 113-136.

- Turner, Bryan (1985) The Body and Society: Explorations In Social Theory. Oxford, Basil Blackwell.

- Weiss, Gail (1999) Body Images: Embodiment as Intercorporeality. New York, Routledge.

\section{Vebografija}

- Dourish Paul, Embodied Interaction: Exploring the Fondations of a New Approach to HCI, dostupno na: [Pristupljeno: 18. 02. 2021, 16.34].

- Gremmler, Tobias, Kung Fu Motion Visualization, dostupno na: dostupno na: https://vimeo.com/163153865, [Pristupljeno: 18. 02. 2021, 21.30].

- Starner, Thad, Wearable Computers as Intelligent Agents, GVU Center, College of Computing, Georgia Institute of Technology, dostupno na: http://www.cc.gatech.edu/ thad/p/032_50_misc/wearable-computers-as-intelligent-agents.pdf [Pristupljeno: 18. 02. 2021, 14:39]. 
Marija Tavčar

Faculty of Contemporary Arts, Belgrade University Business Academy in Novi Sad

PERFORMING BODY IN VIRTUAL COSTUME

\begin{abstract}
The aim of this paper is to define the term "virtual costume" as a conceptual framework and use it to analyze embodiment of the performer dressed in motion capture system in a context of virtual dance. Fused with technology, performing body is established as multiplied, augmented and in flux. By using the theoretical concepts of Joanne Entwistle "dress as embodied practice", Susan Kozel's definition of performance, and Sofia Pantouvaki's and Aoife Monks's theories of "costume", the performing body is described in this study as a constant process of (re)configuration and (re)definition. The article further examines in what way the technology implemented in costume can influence and (trans)form the performer using a case study: Kung Fu Motion Visualization by Tobias Gremler.
\end{abstract}

Key words

virtual costume, costume, performance, motion capture, virtual dance 